\title{
FERTILIDADE E COMPACTAÇÃO DOS SOLOS DA MICROBACIA DO CÓRREGO PANTANINHO, EM IRAÍ DE MINAS (MG)
}

\author{
Andréa Ríspoli Bernardino \\ Bolsista de Aperfeiçoamento Científico - CNPq \\ Samuel do Carmo Lima \\ Prof. Dr. do Departamento de Geografia - UFU
}

RESUMO: As características pedológicas da microbacia do córrego Pantaninho estão sendo estudadas com a finalidade de subsidiar os estudos que visam realizar um diagnóstico ambiental da área, para estabelecer indicadores ambientais de sustentabilidade. Este trabalho enfoca a compactação do solo e os manejos que podem produzir redução da estabilidade dos agregados, adensamento das camadas do solo, redução da porosidade, e por fim reduzir a intensidade das trocas que são determinadas pelas modificações da dinâmica da água.

Palavras Chaves: solos, fertilidade, erosão, compactação

\section{INTRODUÇÃO}

A agricultura brasileira encontra-se frente a um desafio envolvendo aspectos sociais, econômicos e ambientais. Os sistemas agroalimentares nos cerrados passam por uma situação paradoxal. Ao mesmo tempo em que têm que alcançar produtividades cada vez mais elevadas para serem rentáveis, têm que reduzir a exclusão social porque passam os pequenos produtores que estão ficando à margem do mercado e dos programas governamentais de desenvolvimento para a região, para que haja sustentabilidade social. Ao mesmo tempo em que é necessário expandir a produção é necessário reduzir o uso excessivo de adubos e produtos fitossanitários, reduzir a compactação dos solos, para que haja sustentabilidade ambiental e por vias indiretas sustentabilidade econômica.

Nas pressões que decorrem desses desafios, o que se requer são novos métodos de produção agropecuária que venham a reduzir os impactos ambientais, assegurando altos níveis de pureza e não-toxidade dos alimentos. Para vencer esse desafio, é fundamental o acompanhamento de indicadores ambientais de sustentabilidade confiáveis, o que permitirá o estabelecimento de metas devidamente qualificadas e quantificadas, que poderão direcionar o uso de práticas e de tecnologias agropecuárias no sentido de se atingir no futuro, a sustentabilidade ambiental dos sistemas de produção.

Os indicadores de sustentabilidade a que se deseja chegar, devem ser capazes de avaliar o comportamento do agroecossistema em relação à produtividade, se alto ou baixo rendimento; à estabilidade, se a capacidade de produzir se mantém constante; à elasticidade se existe capacidade de recuperação do sistema frente a fatores externos; e à equidade se há distribuição eqüitativa dos recursos econômicos e dos benefícios ou riscos gerados pelo manejo do sistema. 
O objetivo deste trabalho é caracterizar as condições pedológicas da microbacia do córrego Pantaninho relacionadas aos processos de compactação do solo e avaliar os manejos que podem produzir uma redução da estabilidade dos agregados, adensamento das camadas do solo, redução da porosidade, e por fim reduzir a intensidade das trocas que são determinadas pelas modificações da dinâmica da água. As avaliações de compactação do solo, erosão e retenção de umidade nos solos, bem como a avaliação das práticas agrícolas na microbacia do córrego Pantaninho, visam a identificação de indicadores ambientais de sustentabilidade para se determinar os potenciais e os limites de uma ocupação agroecológica sustentável para sistemas agroalimentares no cerrado.

\section{LOCALIZAÇÃO DA ÁREA DE ESTUDO}

A microbacia do córrego Pantaninho está inserida nos municípios de Iraí de Minas (MG) e Romaria (MG), no setor centro sudoeste do Estado de Minas Gerais e localiza-se entre as coordenadas geográficas $18^{\circ} 57^{\prime}$ e $19^{\circ} 06^{\prime}$ de Latitude Sul, 47'29' e 4740' de Longitude Oeste de Greenwich.

\section{METODOLOGIA}

$\mathrm{Na}$ realização deste trabalho foram utilizadas imagens de TM/LANDSAT 5 , escala 1:100.000, composição colorida, bandas 3B, 4R, 5G, de 1995, e cartas topográficas do IBGE, escala 1:100.000, para traçar a drenagem, as principais estradas, delimitar as unidades fisiográficas da área de estudo, e mapear os solos hidromórficos. Utilizamos também as fotografias aéreas pancromáticas de 1979, na escala de 1:25.000, do IBC/GERCA com estereoscópio de espelho, para compartimentação topomórfica e para definir os pontos de observação de campo e coleta de amostras. As fotografias aéreas foram utilizadas, também, para delimitação das unidades pedológicas com base na identificação das unidades fisiográficas da paisagem na área de estudo. Através de um levantamento exploratório, estabeleceu-se a legenda preliminar que foi aperfeiçoada com o levantamento sistemático.

No levantamento sistemático verificou-se os pontos assinalados na fotointerpretação e delimitou-se, no mapa, com mais precisão, as unidades da legenda. As observações de campo para descrição morfológica dos solos foram realizadas em oito perfis.

Foram coletadas amostras referentes aos horizontes de cada perfil observado, que foram acondicionadas em sacos plásticos, devidamente etiquetadas e, posteriormente, levadas ao laboratório para análises físicas e químicas. Nos trabalhos de campo foram utilizados trado do tipo holandês, enxadão, pá, faca, lupa, carta de cor de MUNSEL, clinômetro, bússola, caderneta de campo, máquina fotográfica, sacos plásticos para acondicionamento de amostras, fita métrica, etc.

As amostras foram secas ao ar, destorroadas e passadas em peneira com abertura de $2 \mathrm{~mm}$ de diâmetro. Na fração inferior a $2 \mathrm{~mm}$ (terra seca ao ar) foram feitas as determinações físicas e químicas conforme procedimentos descritos por EMBRAPA (1979). Os ensaios de infiltração (utilizando infiltrômetro de cilindro duplo) e densidade aparente (método do anel volumétrico) foram realizadas conforme EMBRAPA (1979) e PROCTOR (1977).

A identificação dos solos baseou-se nos conceitos de classes de solos estabelecidos pela equipe de pedologia do Serviço Nacional de Levantamentos e Classificação de Solos, SNLCS/ EMBRAPA (1979). 


\section{RESULTADOS E DISCUSSÕES}

A agricultura na microbacia do Córrego Pantaninho é intensiva em médias e grandes propriedades com uso intensivo de irrigação por meio de pivô central, insumos, agrotóxicos, pesticidas e maquinário pesado, com até 3 safras por ano. Predominam as culturas de soja, café, milho, feijão, sorgo, milheto e ervilha. A pecuária se restringe a duas pequenas áreas que, segundo informações do proprietário, brevemente serão substituídas por cultivos agrícolas.

A microbacia do córrego Pantaninho é constituída exclusivamente pelo córrego Pantaninho, não recebendo contribuição de outros cursos d'água. Sua única nascente apresenta-se em forma de anfiteatro, com vertentes muito suaves. É nítido o limite da faixa de inundação, composta por gramíneas e ciperáceas, características das áreas de vereda, com o cerrado que ocupa a faixa marginal da vereda. Aproximadamente 500 metros a juzante da nascente é que o canal do córrego começa a se formar. Ao longo do eixo de drenagem não detectamos a presença contínua dos buritis, que aparecem somente em torno da cabeceira e no baixo curso. O comprimento maior da faixa de inundação, transversal ao eixo de drenagem, é de aproximadamente 250 metros. Apresenta uma litologia de argilitos e siltitos, como também, arenitos conglomeráticos com clastos vulcânicos, representantes da Formação Uberaba. O relevo possui uma topografia que varia de plana a suave ondulada, com declividades quase sempre menores que $3 \%$,

Foi observado na vertente direita do Pantaninho, a partir do médio curso, a existência de uma ruptura de declive que torna-se mais íngreme em direção à foz. Esta ruptura é sustentada por uma couraça laterítica constituída de concreções ferruginosas e seixos de dimensões que variam de milímetros até $40 \mathrm{~cm}$. Este material tem sido utilizado pelos fazendeiros no cascalhamento das estradas. Sob esta ruptura não há vestígios de hidromorfismo, sendo a cobertura vegetal constituída inicialmente por campo sujo e à medida que se dirige para a foz, onde o vale é mais encaixado, aparece uma mata mesofítica densa.

Nesta porção do Pantaninho, as vertentes são dissimétricas, tendo a vertente direita como característica principal, a ruptura cuja declividade se aproxima dos $45^{\circ}$. Já a vertente esquerda, a característica principal é o hidromorfismo, inclusive com a presença de covoais concentrados em alguns pontos à margem, onde começa a acentuar a declividade. Esta vertente tem um grau de inclinação menor que a vertente direita, com uma ruptura bastante insipiente e sem 0 afloramento da carapaça laterítica, a não ser pela presença de couraças espalhadas pela superfície próxima ao último represamento do córrego Pantaninho.

Observa-se através das fotografias aéreas de 1979, a evidência de covoais, no baixo curso na margem esquerda. No entanto, hoje estes covoais foram tomados por reflorestamento de pinus e plantação de soja, o que provocou a drenagem desta área.

No levantamento de solos realizado por MENDONÇA (1997), encontrou-se na microbacia do córrego Pantaninho somente duas classes de solo: Solos Hidromórficos (364 ha) no fundo do vale, e Latossolos com textura argilosa medianamente ácidos nos topos e vertentes (3401 ha). 
TABELA 1 - Solos da microbacia do córrego Pantaninho

\begin{tabular}{lrrc}
\hline CATEGORIA & $\mathrm{km}^{2}$ & ha & $\%$ \\
\hline Latossolo Vermelho & 34,01 & 3401 & 88,9 \\
amarelo & & & \\
Hidromórfico & 3,64 & 364 & 9,5 \\
Represa & 0,61 & 61 & 1,6 \\
\hline TOTAL & 38,26 & 3,826 & 100 \\
\hline
\end{tabular}

Fonte: MENDONÇA (1997).

Os Latossolos apresentam cores 10 YR e 7,5 YR bem homogêneas ao longo do perfil e textura argilosa. Destes solos $50 \%$ são distróficos e $50 \%$ epieutróficos. Estes últimos são predominantemente representados por áreas cultivadas, o que evidencia uma ação corretiva pelo uso de fertilizantes.

Os perfis analisados apresentaram os seguintes valores: teores de areia no horizonte "A" variando de 9 a $23 \%$, e de argila variando de 35 a $60 \%$. No horizonte "B", os teores de areia variam de 7 a $34 \%$, e os de argila de 42 a $65 \%$. Em ambos os horizontes os teores de silte são altos, com média de $35 \%$ e tendência a declinar em profundidade, ao contrário da argila, que tende a aumentar em profundidade.

\section{Fertilidade}

A fertilidadade natural dos solos encontra-se relacionada à herança de sua base litológica, na ciclagem de nutrientes definida por um circuito existente na relação solo - vegetação - solo e pela intensidade de trocas químicas determinadas pela dinâmica da água. Entretanto, como os solos da microbacia do Córrego Pantaninho vêm sendo cultivados desde o início dos anos 80 , quando foi implantado o PRODECER, com agricultura comercial de alto rendimento, as adubações químicas sucessivas parece ter melhorado a constituição química desses solos. A cerca de dois anos, o plantio direto substituiu o plantio convencional, em todas as propriedades da microbacia, e seria importante avaliar o balanço químico desses solos, ao longo do tempo.

A capacidade de troca catiônica $(T)$ no horizonte "A" apresentou valores de 5 a $9 \mathrm{mEq} / 100 \mathrm{~g}$. No horizonte "B" essa variação encontra-se entre 3 e $8 \mathrm{mEq} / 100 \mathrm{~g}$. Os valores encontrados para a soma das bases (SB) tiveram uma variação de 0,7 a 5,7 mEq/ $100 \mathrm{~g}$ no horizonte "A". No horizonte "B" estes valores são um pouco menores, variando entre 0,2 e 4,2 mEq/100g. Nos perfis analisados em área de cultivo, são encontrados valores mais altos. A saturação de bases (V\%) oscila entre 16 e $71 \%$ no horizonte "A", e entre 4 e $57 \%$ no horizonte "B". Da mesma forma que os valores de soma das bases (SB), os perfis analisados em áreas de cultivo, apresentaram os maiores índices em saturação de bases, tanto no horizonte "A" quanto no "B", o que era de se esperar depois de mais de 15 anos de adubações sucessivas.

Alumínio e hidrogênio trocáveis possuem valores de 2,3 a 6,3 mEq/100g no horizonte " $A$ ", e de 1,9 a 5,2 mEq/100g no horizonte "B". A saturação de alumínio $(\mathrm{m})$ varia de 0 a $23 \%$ no horizonte "A", e de 10 a $57 \%$ no horizonte "B". Quanto a esta grande variação, vale ressaltar que nos perfis 4, $5 \mathrm{e}$ 19, que correspondem a áreas de cultivo, não foi encontrado teor de alumínio. Quanto ao $\mathrm{pH}$ no horizonte " $A$ ", houve variação de 4,9 a 6,2 , enquanto no horizonte " $B$ " variou de 4,6 a 6,3 . Nos perfis em área de cultivo estes valores foram superiores a 5,6. Há controvérsia sobre o efeito do plantio direto 
sobre a acidez do solo, com estudos demonstrando que esta pode se elevar e outros, ao contrário, demonstrando que a acidez pode se reduzir (SÁ 1993).

Os solos Hidromórficos estão localizados ao longo do canal de drenagem do córrego Pantaninho. Ocupam uma área de $3,64 \mathrm{Km} 2$, equivalente a $9,5 \%$ da área total mapeada. Apresentam cores 10 YR e 2,5 Y, textura argilosa, e de 4 a $5 \%$ de matéria orgânica no horizonte "A". Possuem excesso d'água em condições variáveis, em função de sua posição relativa ao centro da drenagem.

Os perfis analisados apresentaram os seguintes valores: teores de areia no horizonte "A" com média de $15 \%$, e argila variando de 46 a $51 \%$. No horizonte "B", os teores de areia ficaram em torno de $15 \%$, enquanto os de argila variaram de 46 a $68 \%$. Os teores de silte no horizonte "A" variaram de 35 a $38 \%$, e no horizonte "B" de 16 a $38 \%$.

A capacidade de troca catiônica ( $T$ ) no horizonte "A" apontou $6 \mathrm{mEq} / 100 \mathrm{~g}$, e no horizonte "B", $3 \mathrm{mEq} / 100 \mathrm{~g}$. Os valores encontrados para a soma das bases (SB) tiveram uma variação de 0,3 a 3,3 mEq/100g no horizonte "A". No horizonte " $B$ ", estes valores são bem menores, variando entre 0,2 e $0,4 \mathrm{mEq} / 100 \mathrm{~g}$. A saturação de bases (V\%) oscila entre 5 e $47 \%$ no horizonte " $A$ " e entre 5 e $11 \%$ no horizonte "B". Estes altos valores de $V \%$ no horizonte "A", refere-se ao fato deste perfil analisado ser localizado em área de cultivo.

Alumínio e hidrogênio trocáveis possuem valores de 3,8 a $5,6 \mathrm{mEq} / 100 \mathrm{~g}$ no horizonte " $A$ ", e de 2,8 a $3,3 \mathrm{mEq} / 100 \mathrm{~g}$ no horizonte "B". A saturação de alumínio $(\mathrm{m})$ varia de 33 a $68 \%$ no horizonte "A", e no horizonte "B" não há ocorrência deste elemento. Com relação ao teor de $\mathrm{pH}$ nestes solos, no horizonte "A" houve variação de 4,8 a 5,7 , enquanto no horizonte " $B$ " ficou em torno de 5,2 .
Os valores de $\mathrm{S}$ (soma de bases) variaram de 0,7 a 5,7 $\mathrm{mEq} / 100 \mathrm{~g}$ no horizonte "A" e 0,2 a 4,2 mEq/100g no horizonte "B". $\mathrm{O}$ valor $\mathrm{V}$ (saturação de bases) variou de 16 a $71 \%$ no horizonte " $A$ " e de 4 a $57 \%$ no horizonte "B". A saturação de Alumínio apresentou variações de 0 a $23 \%$ no horizonte "A" e no horizonte " $B$ " entre 10 e $57 \%$. Mesmo em profundidade, a saturação de alumínio não se mostrou elevada, o que pode ser correlacionável com a moderada acidez do solo. Em geral, os perfis analisados em área de cultivo são fortemente ácidos e de baixa fertilidade, sendo considerados epiálicos e distróficos.

\section{Compactação}

A compactação dos solos é um dos mais importantes problemas de degradação ambiental provocados por uso e manejo inadequados como o preparo do solo em condições desfavoráveis de umidade, implementos de preparo mal regulados, utilização excessiva de grade. Afeta a estrutura do solo, modificando o seu sistema de poros. Caracteriza-se pelo adensamento das camadas do solo e, em conseqüência disto, aumento da resistência de penetração das raízes das plantas, causando deficiências de oxigênio para as raízes. Influencia diretamente a condutividade, a capacidade de infiltração e a retenção da água. Ainda, pode-se dizer do aumento da enxurrada e da erosão. Prejudica o desenvolvimento da planta na redução da emergência e do estande, na redução do desenvolvimento radicular $e$, conseqüentemente, redução da produtividade. A identificação do processo de compactação do solo pode ser feita mediante avaliação do sistema radicular, pela determinação da densidade do solo e por medidas da resistência do solo, com penetrômetros de impactos.

A manutenção da umidade que existe na massa porosa do solo é importante para que a mesma permaneça à disposição das 
plantas, desenvolvendo os sistemas radiculares e permitindo a absorção da água e dos nutrientes disponíveis. A baixa capacidade de retenção de água e nutrientes dos solos de textura arenosa dificulta o desenvolvimento da maioria das culturas.

A intensa utilização de implementos agrícolas de grande porte, considerada como a razão do sucesso econômico dos sistemas agroalimentares dos cerrados tem causado a compactação dos solos. A erosão está relacionada aos processos de desagregação, de arrastamento e de deposição das partículas constituintes do solo provocados, principalmente, pela ação da água das chuvas. Para NISHIYAMA et alii (1995), os fatores que influenciam nos processos de erosão são: a textura dos materiais inconsolidados, o tipo de argilomineral presente, o grau de cimentação, a capacidade de infiltração, a forma e comprimento da encosta, a declividade, a cobertura vegetal, o uso do solo e a erosividade atuando de forma mais ou menos interdependentes.

O controle da erosão agrícola consiste no uso adequado de práticas de conservação e manejo do solo e das culturas, a fim de reduzir o transporte das partículas para terrenos mais baixos, pois as explorações não planejadas dos recursos podem acarretar em modificações irreversíveis ao meio ambiente.

Algumas alternativas para o aumento da infiltração e para a redução da erosão são: diminuição da desagregação da estrutura do solo, mediante o controle do tráfico de máquinas e redução do número de operações de revolvimento; melhoria das condições físicas do solo pela incorporação da matéria orgânica e rotação de cultura; descompactação do solo com o uso de subsolagem e esclarificação; redução do volume e da velocidade de escoamento superficial das águas excedentes mediante a implantação de sistemas de culturas em faixas de rotação de culturas e de terraceamento.

A taxa de infiltração de água no solo é um dos parâmetros de avaliação da qualidade estrutural do solo. Uma baixa taxa de infiltração da água no solo pode ocorrer devido a desagregação de sua estrutura por métodos impróprios de preparo do solo e cultivo, e pela retirada indiscriminada da cobertura vegetal. O uso e o manejo do solo podem modificar as características físicas do solo e, por isso, podem influenciar decisivamente nas taxas de infiltração. Os valores de infiltração encontrados para esses solos foram relativamente elevados, variando para os diferentes usos. Para a área de cultivo de soja obtivemos $240 \mathrm{~mm}$, em área de pastagem $132 \mathrm{~mm}$ e em área de cultivo de café $84 \mathrm{~mm}$. Isso indica que o plantio direto tem sido eficiente na manutenção e até na melhoria da estruturação do solo. 0 valor obtido da densidade aparente realizada para uma das amostras coletadas no córrego Pantaninho foi de $2,72 \mathrm{~g} / \mathrm{cm}^{3}$.

\section{CONSIDERAÇÕES FINAIS}

O que tem agravado cada vez mais o processo de degradação do solo em áreas de cerrado é a compactação e a impermeabilização produzidas pelas atividades do maquinário agrícola. A compactação e a erosão dos solos já podem ser arroladas como dois dos mais importantes problemas de degradação ambiental em conseqüência da mecanização.

Nos solos da microbacia do Córrego Pantaninho que são, predominantemente, Latossolos de textura argilosa, após mais de 15 anos de agricultura intensiva já apresentavam um processo de degradação, visível no campo, com ravinamentos e compactação das camadas aráveis. Entretanto, após a adoção do sistema de 
cultivo em plnatio direto, esses problemas já começaram a ser amenizados.

A adoção do plantio direto, sem dúvida, tem contribuído em muito para a manutenção e recuperação da estrutura desses solos. O plantio direto na resteva da cultura anterior tem-se mostrado uma das alternativas para o manejo correto e sustentável dos sistemas agrícolas intensivos nos cerrado, porque melhora as propriedades físicas do solo, ao conservar uma cobertura que protege a superfície do solo da radiação solar e do impacto de gotas da chuva. O sistema de plantio direto pode auxiliar na fertilização dos solos a partir da incorporação de uma massa orgânica (adubação verde), que também contribui para a manutenção e aumento de suas populações microbiológicas.

Se o plantio direto pode permitir o ajustamento da sanidade física dos solos, por outro lado, parece ter magnificado os problemas de contaminação química do solo e dos mananciais de água, bem como problemas fitossanitários com 0 aparecimento de novas doenças nos cultivos. Diante dessas considerações, não podemos deixar de concordar que ainda não encontramos a solução definitiva e completa para os problemas ambientais da produção agroalimentar. Entretanto, estamos num caminho que pode nos levar a melhoria da qualidade ambiental dos alimentos e da sanidade do meio ambiente.

\section{REFERÊNCIAS BIBLIOGRÁFICAS}

\section{EMBRAPA Manual de Métodos e Análise} de Solo. SNCLS - Serviço Nacional de Levantamento e Conservação de Solos, Rio de Janeiro, 1979.

MENDONÇA, M.G. Os Solos e a Sustentabilidade Ambiental nas Microbacias Pantaninho e Divisa em Iraí de Minas-MG. Uberlândia.
Departamento de Geografia - UFU. (Monografia de Graduação), 1997.

NISHIYAMA, L. et al. Contribuição Preliminar aos Estudos de Erosão no Município de Uberlândia-MG: Avaliação sob o Aspecto de Infiltração da Água em Ensaios in situ com o Uso de Infiltrômetro de Duplo Cilindro. IV Simpósio de Geologia do Sudeste. Anais. Sociedade Brasileira de Geologia e Unesp (org.) 1995, Águas de São Pedro. (Caderno de Resumos).

PROCTOR, R.R. Fundamental Principles of Soil Compaction. Engineering News Record. Ago/Set, 1933. In: VARGAS, M. Introdução à Mecânica dos Solos. São Paulo, McGraw-Hill do Brasil/ EDUSP, 1977.

SÁ, J.C. de M. Manejo de fertilidade no plantio direto. Fundação $A B C$ para assistência e divulgação técnica agropecuária. Carambeí/Castro (PR), 1993. 